\title{
Malaysia Secondary Students' Conceptions about the Particulate Nature of Matter
}

\author{
Nurdiana Abdullah \\ Faculty of Education \\ University of Technology \\ Malaysia Johor, Malaysia
}

\author{
Syuhaida Ismail \\ RAZAK School of \\ Engineering and Advanced \\ Technology University of \\ Technology Malaysia Jalan \\ Semarak, Kuala Lumpur, \\ Malaysia
}

\author{
Johari Surif \\ Faculty of Education \\ University of Technology \\ Malaysia \\ Johor, Malaysia
}

\begin{abstract}
This paper was conducted to determine students' conceptions about the particulate nature of matter (PNM) in daily life events. Five open ended questions from Nature of Matter-Diagnostic Questions (NMDQ) were used to collect the data through questionnaire survey. 32 secondary students were chosen through random sampling for this study. A qualitative and quantitative methodology was used for this investigation. The findings were analyses using descriptive statistics via Statistical Package in the Social Sciences (SPSS) and content analysis. The results showed that the type of conceptual understandings among the students on the submicroscopic level of matter were classified as alternative understanding with scientific fragments. They have alternative conceptions about the submicroscopic level of particles such as the arrangement and relative spacing between the particles in three states of matter, the movement of water particles and solid particles in a liquid and the movement and uniform distribution of liquid molecules in another liquid. Hence, this paper suggests that the instruction on the particulate nature of matter is needed in helping students making connections between the three levels which chemistry can both taught and understood. It is proposed that by emphasizing the three levels of chemistry in describing common, everyday phenomena to which students could relate would make the instruction more effective.
\end{abstract}

Keywords - science education; secondary science students; particulate nature of matter; submicroscopic level; conception

\section{INTRODUCTION}

Learning of chemical concepts involves the teaching of the atomic, molecular and ionic interactions responsible for observes chemical phenomena [1]. This interaction is referred to as the particulate nature of matter (PNM). Everything that takes up space is made up of tiny invisible/indivisible particles with nothing between them are PNM. The scientific aspects of the PNM are: matter is made up of particles, particles are in continuous motion or vibration in all three states of matter, nothing exists between the particles of matter, the distances between particles of a solid and liquid are similar, the attraction forces exist between the particles of matter and the macroscopic properties of matter are collective properties of the particles and cannot be attributed to a single particle. Understanding the PNM is critical to understand chemistry. Consequently, there are rich and broad base of works that have identified students' alternative conceptions about the PNM [2]. Alternative conception is conceptual understanding which variance with the scientifically accepted norms [3]. Numerous studies have highlighted students' difficulties in grasping the PNM. It was illustrated quite early on that young students have alternative conceptions associated with the PNM. In fact, even undergraduate chemistry students have alternative conceptions associated with the PNM [4].

Chemistry has three levels of study: symbolic, macroscopic, and submicroscopic (particulate and molecular) [1]. At the macroscopic level, chemistry involves the observable phenomena which include references to students' everyday experiences such as melting ice cream or a corroding nail. At the submicroscopic level, a corroding nail becomes a chemical process in which iron atoms of the nail react with oxygen molecules in the air and eventually, iron oxide molecules are produced. Another way to represent this process is by using a chemical equation with symbols, formulas and numbers, such as $4 \mathrm{Fe}(\mathrm{s})+3 \mathrm{O}_{2}(\mathrm{~g}) \rightarrow 2 \mathrm{Fe}_{2} \mathrm{O}_{3}(\mathrm{~s})$. Most students are unable to visualize the submicroscopic and symbolic levels of representations as chemists do [5-6]. Students' difficulties have been attributed to several factors, such as the perceptual nature of atoms and molecules [7] and students' incomplete or inappropriate mental models [5]. A mental model is the learners' personal mental representation of an idea or concept. It is a window into the learners' understanding and can be used 
by the learner to give explanations, make predictions and provide reasoning [8].

The concept of matter is essential to chemistry since chemistry is a science of matter and its transformations. Educators would agree that PNM is part of the heart of theoretical chemistry and the particle theory of matter is a key component in several science education curricula from as early as upper primary school years to various stages of secondary school [9-10]. Appropriate understanding of particle theory is essential to the learning of chemical concepts [9]. Due to this importance, numerous studies related to the PNM have emerged in the last three decades. In fact, the research into students' conceptions of the PNM showed that students in every grade level easily develop either spontaneous or instruction induced alternative conceptions about the PNM [7, 9, 11-22].

\section{AIM}

It is well-known that the particulate nature of matter is a difficult concept and hence students have many problems while learning this concept. It also seems difficult for students to apply the particle model consistently across different substances [16]. Although many international studies about students' understanding of the PNM have been carried out by using paper-pencil tests, open-ended questions and/or interviews so far, research related to this concept which also focuses on student drawing at the submicroscopic level is very limited in Malaysia. There are some advantages of drawing method. For example, students' drawings provide to reflect their thoughts, feelings and minds [23]. Moreover, it can be useful alternative expression type for students having difficulty describing ideas verbally [24]. With this in mind, this study may be a starting point for other researchers in Malaysia. Such data may give teachers, researchers and educators valuable feedback related to students background and alternative conceptions as well as the effectiveness of their instruction. Within the domain, the study aims to synthesize student views about the PNM within the context of daily life events.

\section{METHODOLOGY}

32 students from one secondary school were chosen by random sampling for this study to involve in survey. During the survey, the students were asked to complete the test. The survey was lasted about one hour. Five open-ended questions from Nature of Matter-Diagnostic Questions (NMDQ) [25] were asked and the questions were related to concept matter as discrete particles, the motion of the gas particles, the arrangement and relative spacing between the particles in three states of matter, the movement of water particles and solid particles in a liquid and the movement and uniform distribution of liquid molecule in another liquid.

The content validity of the question was achieved by asking experts and science and chemistry teachers to evaluate them. In the data analysis process, students' responses were examined thematically and classified into six categories: scientific understanding, scientific fragments, scientific with alternative fragments, alternative with scientific fragments, alternative fragments and no understanding [26-29]. The categories are described in detail in Table I.

TABLE I. TYPE OF CONCEPTUAL UNDERSTANDINGS AND CRITERIA

\begin{tabular}{|l|l|}
\hline \multicolumn{1}{|c|}{$\begin{array}{c}\text { Type of } \\
\text { Understanding }\end{array}$} & \multicolumn{1}{|c|}{ Criteria } \\
\hline $\begin{array}{l}\text { Scientific } \\
\text { understanding }\end{array}$ & $\begin{array}{l}\text { Must include all of the scientific } \\
\text { conceptual understanding criteria. }\end{array}$ \\
\hline Scientific fragments & $\begin{array}{l}\text { Must include scientific criteria of } \\
\text { "Matter is made up of tiny particles" } \\
\text { and includes a subset of the other } \\
\text { four scientific criteria, but not all of } \\
\text { them. }\end{array}$ \\
\hline $\begin{array}{l}\text { Scientific with } \\
\text { alternative fragments }\end{array}$ & $\begin{array}{l}\text { Must include scientific criteria of } \\
\text { "Matter is made up of tiny particles" } \\
\text { at least in two states of matter, and } \\
\text { includes a subset of the other four } \\
\text { aspects of the PNM with at most } \\
\text { three alternative criteria. }\end{array}$ \\
\hline $\begin{array}{l}\text { Alternative } \\
\text { scientific fragments }\end{array}$ & $\begin{array}{l}\text { Include a subset of the alternative } \\
\text { criteria indicated in alternative } \\
\text { fragments section with two scientific } \\
\text { aspects of the PNM }\end{array}$ \\
\hline Alternative fragments & $\begin{array}{l}\text { Include a subset of conceptual } \\
\text { understandings that are in conflict } \\
\text { with scientific aspects of the PNM } \\
\text { with no fragments of scientific } \\
\text { understanding. The alternative } \\
\text { conceptions emerged from the data. }\end{array}$ \\
\hline No understanding & $\begin{array}{l}\text { There is no or enough evidence to } \\
\text { judge students understanding as } \\
\text { scientific or alternative understanding } \\
\text { of the PNM }\end{array}$ \\
\hline
\end{tabular}

To assure validity of the classification, the student responses were classified by two researchers. In each of the five questions, the two researchers agreed in about 90 percent or more of the classifications. If there was a disagreement in classification, it was discussed in detail and an agreement was reached. Students' written responses to the Nature of MatterDiagnostic Questions (NMDQ) were typed and the figures that they drew as part of their responses were scanned to allow the researcher to be able to easily reads, code and organize the data. The written responses (both pictorial and verbal) were throughly analysed by qualitative analysis: reading, rereading and coding in order to identify the participants' type of conceptual understandings of the PNM and quantitative analysis: numeric values for frequency and percentage. 


\section{RESULTS AND DISCUSSION}

The findings of the study are presented below.

A. What are the types of conceptual understandings held by students about PNM?

Table II summarizes the students' types of conceptual understandings held by students about PNM. Regarding the six types of conceptual understanding categories, the students' understandings of the PNM were considered to be less scientific or mostly non-scientific. As shown in Table II, majority of the students' conceptual understanding were classified as alternative understanding with scientific fragments. These students showed alternative conceptions in more than three aspects of the PNM with one or two scientific fragments. Only one of the 32 (3 percent) students' conceptual understandings was classified as alternative fragment that included a subset of a conception with no evidence of understanding any scientific aspects of the PNM. No students' conceptual understanding was classified as either scientific understanding, scientific fragments and scientific with alternative fragments.

Table III summarized the frequency of students' correct answers to NMDQ test based on students' pictorial representations and verbal explanations. This finding showed that all students held a range of alternative conceptions of the PNM and the conceptions occurred in various frequencies. That is, many of the students exhibited an understanding of pieces of the PNM, but all students failed to create a connected whole picture of the PNM. Thus, none of the students' conceptual understandings were classified as scientific, scientific fragments or scientific with alternative fragments. As shown in Table III, only one of the five questions answered with correct response. Even though majority of the students were able to perceive matter as being discrete particles in the three states of matter for question 1 , they all held a combined set of the alternative conceptions about various aspects of the PNM for question 2, 3, 4 and 5. For example, the uniform distribution of gas particles and the density of gas particles for question 2, the arrangement of particles in liquid and the distances between the particles of liquid for question 3 and 4 and the motion of particles in liquid for question 5.

TABLE II. TYPE OF STUDENT CONCEPTUAL UNDERSTANDING ABOUT PARTICULATE NATURE OF MATTER (PNM)

\begin{tabular}{|l|c|c|}
\hline $\begin{array}{c}\text { Type of Conceptual } \\
\text { Understanding }\end{array}$ & Frequency (N) & Percentage (\%) \\
\hline $\begin{array}{l}\text { Scientific } \\
\text { understanding }\end{array}$ & - & - \\
\hline Scientific fragments & - & - \\
\hline $\begin{array}{l}\text { Scientific with } \\
\text { alternative fragments }\end{array}$ & - & - \\
\hline Alternative with & 31 & 97 \\
\hline
\end{tabular}

\begin{tabular}{|l|c|c|}
\hline scientific fragments & & 3 \\
\hline $\begin{array}{l}\text { Alternative } \\
\text { fragments }\end{array}$ & 1 & \\
\hline No understanding & - & - \\
\hline
\end{tabular}

TABLE III. PERCENTAGES OF STUDENTS' CORRECT ANSWERS TO NMDQ TEST

\begin{tabular}{|c|c|c|c|}
\hline Questions & $\begin{array}{c}\text { Frequency } \\
\text { (N) }\end{array}$ & $\begin{array}{c}\text { Percentage } \\
(\%)\end{array}$ & $\begin{array}{c}\text { Students' } \\
\text { Alternative } \\
\text { Conception } \\
\end{array}$ \\
\hline 1 & 32 & 100 & - \\
\hline 2 & 26 & 81 & $\begin{array}{c}\text { the uniform } \\
\text { distribution of gas } \\
\text { particles, the } \\
\text { density of gas } \\
\text { particles }\end{array}$ \\
\hline $\begin{array}{c}3 \\
\text { (Drawing) }\end{array}$ & 2 & 6 & $\begin{array}{l}\text { the arrangement of } \\
\text { particles in liquid, } \\
\text { the distances } \\
\text { between the } \\
\text { particles of liquid }\end{array}$ \\
\hline $\begin{array}{c}3 \\
\text { (Explanation) }\end{array}$ & 2 & 6 & $\begin{array}{l}\text { the arrangement of } \\
\text { particles in gas, } \\
\text { liquid and solid }\end{array}$ \\
\hline $\begin{array}{c}4 \\
\text { (Drawing) }\end{array}$ & 2 & 6 & $\begin{array}{l}\text { the arrangement of } \\
\text { particles in liquid, } \\
\text { the distances } \\
\text { between the } \\
\text { particles of liquid }\end{array}$ \\
\hline $\begin{array}{c}4 \\
\text { (Explanation) }\end{array}$ & 4 & 13 & $\begin{array}{l}\text { the arrangement of } \\
\text { particles in liquid, } \\
\text { the distances } \\
\text { between the } \\
\text { particles of liquid }\end{array}$ \\
\hline 5 (Drawing) & 3 & 9 & $\begin{array}{l}\text { the arrangement of } \\
\text { particles in liquid, } \\
\text { the distances } \\
\text { between the } \\
\text { particles of liquid }\end{array}$ \\
\hline $\begin{array}{c}5 \\
\text { (Explanation) }\end{array}$ & 3 & 9 & $\begin{array}{c}\text { the motion of } \\
\text { particles in liquid }\end{array}$ \\
\hline
\end{tabular}


B. What are alternative conceptions held by students about the aspects of the PNM?

Matter as discrete particles

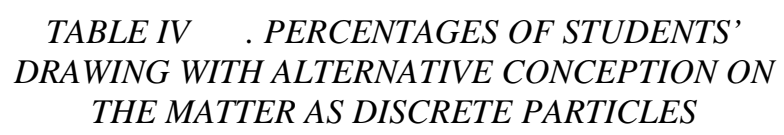

TABLE IV . PERCENTAGES OF STUDENTS' DRAWING WITH ALTERNATIVE CONCEPTION ON THE MATTER AS DISCRETE PARTICLES

\begin{tabular}{|c|c|c|}
\hline Matter & Frequency (N) & Percentage (\%) \\
\hline Solid & - & - \\
\hline Liquid & 32 & 100 \\
\hline Gas & - & - \\
\hline
\end{tabular}

All students (100 percent) were able to draw and perceive matter as being discrete particles in solid and gas. This situation is on the contrary with the studies involving school children that pose obstacles of their appropriate understandings about the properties of matter. A major obstacle is students' intuitive belief that matter is continuous in nature rather than particulate and that the particles in matter are in contact with each other with no empty space between the particles [11, 14, 30]. This demonstrates that majority of the students' possess correct scientific ideas that all matter consists of entities called particles except for liquid. Students' drawings on particles in liquid illustrated that students were not able to pictorially show the distinctive distances and arrangement of particles for the liquid (refer Figure 1 and Figure 2). This finding showed that most of the students could not understand and eventually failed to use the submicroscopic level in particulate nature of matter. This is due to the fact that the students are having difficulties in understanding submicroscopic level, which is observed by many as challenging [31]. This is supported by Ben-Zvi, Silberstein and Mamlok [32] who claim that the difficulties faced by students in understanding this submicroscopic level are affected by deficient understanding in atom model and how this model can be used in explaining the chemistry phenomena and law. These findings point to the challenges of submicroscopic representations of phenomena that depend on cooperative interactions amongst particles rather than on the characteristics of the particles themselves.

On the other hand, all students also perceived that particles in liquid are further apart than particles in a solid. This situation occurred because students are normally able to correctly depict the particles as arranged in a 'typical' solid after the learning session (Figure 3). However, particles in liquid are often inaccurately drawn as being further apart than those in solid (Figure 4) as a kind of intermediate between solid and gas particle arrangements [33]. Figure 5 demonstrated a more accurate depiction of the arrangement of particles in the liquid phase. The particles remain touching as in solid but have lost their regular arrangement and hence exist in a random and overlapping pattern in three dimensions.

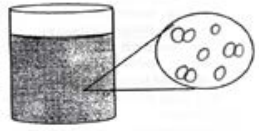

Fig.1 Drawing that represent the student 2's alternative conceptions of the distinctive distances of particles in liquid

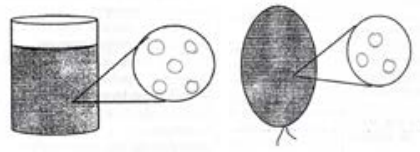

Fig. 2. Drawings that represent the student 32's alternative conceptions of the distinctive distances of particles in liquid which same as distinctive distances of particles in gas

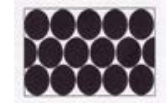

Fig. 3. Particles in solid

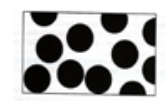

Fig. 4. Particles in liquid (alternative conception)

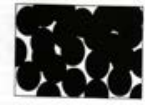

Fig. 5. Scientific depiction of particles in liquid

The motion and density of the gas particles

TABLE V. PERCENTAGES OF STUDENTS'

DRAWING WITH ALTERNATIVE CONCEPTION ON THE MOTION AND DENSITY OF THE GAS PARTICLES

\begin{tabular}{|c|c|c|}
\hline Concept & Frequency (N) & Percentage (\%) \\
\hline Motion & - & - \\
\hline Density & 6 & \\
\hline
\end{tabular}

All of students (100 percent) were able to recognize that particles of gas are uniformly distributed in the flask. This demonstrates that the students understood the key concepts that motion is a permanent feature of all particles. However, only six students showed inability to recognize that the density of gases changes when half of the gas is released from the closed container.

From these six students, two of them drew the picture of the air remaining in the flask after some air was removed by using the pump in the condition where the gas particles remained at the bottom of the pump (refer Figure 6). The findings are consistent with the finding of a cross-age study in the USA where they claims that the remaining air in an evacuated flask would remain along the edge of the flask 'trying to bust out'. Based on that research, pumping out the air meant letting out this medium, the genuine air, leaving the particles on the bottom, like fish without water [34]. Another student, on the other hand, drew the gas particles at the middle of the pump (refer Figure 7) whereas another student, drew the gas particles did not and any changes even though certain amount of air has been expelled (refer Figure 8). The disability of the students in accurately drawing the concept of the 
density of gases illustrate that the students failed to understand the idea of the particulate nature of air and that particles of air are being evenly scattered. This situation expected since Stavy [35] who studies the formation of gases during changes of state have indicated that students are unable to conceptualize a gas as being a substance, while many are of the opinion that gas is weightless or is lighter than solids or liquids.

This situation demonstrated the students' inability to understand the movement of gas particles where particles of gas move randomly and rapidly in all directions (gas particles are evenly scattered in any enclosed space). When the air is released, the quantity of gas particle is decreased because the gas particles are expelled through the pump. This situation happens to the fact that air is invisible and in everyday situation its presence is not usually acknowledged [33].

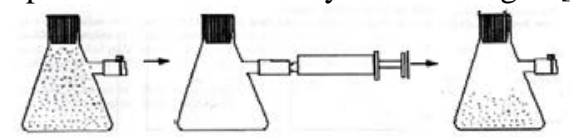

Fig. 6. Drawings that represent student 2's alternative conceptions of the motion and density of gases

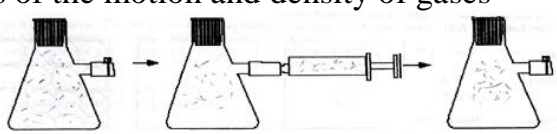

Fig. 7. Drawings that represent student 2's alternative conceptions of the motion of gases

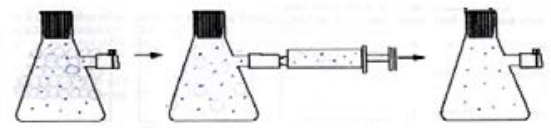

Fig. 8. Drawings that represent student 2's alternative conceptions of the density of gases

The arrangement and relative spacing between the particles in three states of matter

TABLE VI. PERCENTAGES OF STUDENTS' DRAWING WITH ALTERNATIVE CONCEPTION ON THE ARRANGEMENT AND RELATIVE SPACING BETWEEN THE PARTICLES IN THREE STATES OF MATTER

\begin{tabular}{|c|c|c|}
\hline Matter & Frequency (N) & Percentage (\%) \\
\hline Solid & - & - \\
\hline Liquid & 30 & 94 \\
\hline Gas & - & - \\
\hline
\end{tabular}

The results of this paper demonstrated that majority of the students have accurate drawn the solid and gas particles whilst at the same time failed to draw the liquid particles accurately (94 percent). The mistakes in the students' drawings are detected in terms of arrangement of and the relative spacing between the particles of liquids. Only two students were able to draw the liquid particles accurately. For instance, the drawings of respondent 27 and respondent 30 showed alternative conception on the arrangement and relative spacing of liquid as illustrated in Figure 6 and Figure 7.
The students were unable to understand that liquid particles slide each other with random arrangement but they are similarly spaced out as particles of solids. However, students usually believe that the relative distances between particles of liquids are intermediate when compared to the distances between the particles of solids and liquids [12-14, 18, 20, 36].

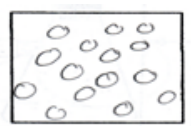

Fig. 9. Drawings that represent student 27's alternative conceptions of the arrangement and relative spacing between the particles in liquid

$$
\begin{array}{|lll|}
\hline & & 0 \\
& \infty & 0 \\
0 & 0 & 0 \\
& 0 & \\
\hline
\end{array}
$$

Fig. 10. Drawings that represent student 30's alternative conceptions of the arrangement and relative spacing between the particles in liquid

TABLE VII. PERCENTAGES OF STUDENTS' EXPLANATION WITH ALTERNATIVE CONCEPTION ON THE ARRANGEMENT AND RELATIVE SPACING BETWEEN THE PARTICLES IN THREE STATES OF MATTER

\begin{tabular}{|c|c|c|}
\hline Matter & Frequency (N) & Percentage (\%) \\
\hline Solid & 26 & 81 \\
\hline Liquid & 28 & 88 \\
\hline Gas & 24 & 75 \\
\hline
\end{tabular}

In terms of explanation aspect, only one student was able to recognize the differences between the three states of matter in terms of arrangement of and the relative spacing between the particles. Majority of the students have alternative conception on the arrangement and the relative spacing between the particles in solid, liquid and gaseous state in their explanations. Explanation by respondent 28 and respondent 25 showed the emergence of alternative conception on the aspect of the arrangement and relative spacing between the particles in three states of matter.

Responses by respondent 28 are [Gas: The arrangement of the particle is far apart and can move freely (Alternative Arrangement and Distance of Gas). Liquid: The arrangement of the particle can freely moving and collides with each other (Alternative Arrangement and Distance of Liquid). Solid: The arrangement of the particle is can only vibrate at their fixed position (Alternative Arrangement and Distance of Solid)] whilst respondent 25's responses are [Gas: The gas particle's distance is very far and the arrangement not attach to each other (Alternative Arrangement of Gas). Liquid: The liquid particle's distance is far and the arrangement not attach to each other (Alternative Arrangement and Distance of Liquid). Solid: The solid particle's distance is near and the arrangement is attach to each other (Alternative Arrangement and Distance of Solid)]. This finding is supported by Adadan [25] who claims that students were not able to pictorially show 
the distinctive patterns for the arrangement of particles and the distances between the particles. For instance, respondent 10 perceived the distances between the particles of liquid as intermediate between the solid and the gas state from his/her statement of [The particles of arrangement is closer than box \#1]. Technically, the distances between the particles of liquids are considered to be similar to the distances between the particles of solids.

\section{The movement of water particles and solid particles in liquid}

\section{TABLE VIII. PERCENTAGES OF STUDENTS' DRAWING WITH ALTERNATIVE CONCEPTION ON THE MOVEMENT OF WATER PARTICLES AND SOLID PARTICLES IN LIQUID}

\begin{tabular}{|c|c|c|}
\hline Matter & Frequency (N) & Percentage (\%) \\
\hline Sugar molecules & 30 & 94 \\
\hline Water molecules & 30 & 94 \\
\hline Aqueous & 4 & 13 \\
\hline
\end{tabular}

Study on students' ability to understand that water particles play the key role in dissolving of a solid due to their (water particle) ability to move and that particles of a solid are uniformly distributed in a liquid when a solid dissolves showed that majority of the students (94 percent) were unable to draw and explain that the particles move randomly and diffuse to all directions. This is based on the drawings given by the students such as respondent 11 who drew four sugar molecules, twelve water molecules and process product via the existence of alternative conception (refer Figure 8) against arrangement and relative spacing between liquid molecules. This finding demonstrated that the students misunderstood the concept of movement of particles for liquid (particles move randomly and slowly, and collide against each other). This situation illustrated that the student assumed the spacing between the particles of liquids is in between the spacing between particles of solids and gases.

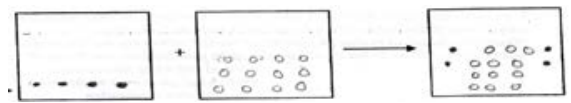

Fig. 11. Drawings that represent student 11's alternative conceptions of the arrangement and relative spacing between the particles of liquids

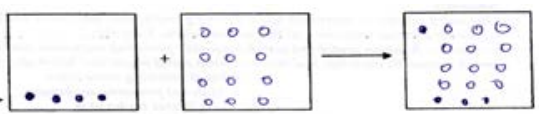

Fig. 12. Drawings that represent student 12's alternative conceptions of the arrangement and relative spacing between the particles of liquids

TABLE IX. PERCENTAGES OF STUDENTS' EXPLANATION WITH ALTERNATIVE CONCEPTION ON THE MOVEMENT OF WATER PARTICLES AND SOLID PARTICLES IN LIQUID

\begin{tabular}{|l|l|l|} 
Matter & Frequency (N) & Percentage (\%) \\
\hline
\end{tabular}

\begin{tabular}{|c|l|l|}
\hline Sugar molecules & 27 & 84 \\
\hline Water molecules & 27 & 84 \\
\hline Aqueous & 28 & 88 \\
\hline
\end{tabular}

Besides, based on the explanation by student, alternative conception emerged against the concept of random movement of liquid particles via their statement of [Box \#1: Because the sugar molecule is solute (Alternative Arrangement and Distance of Solid). Box \#2: Because the water molecules is solvent (Alternative Arrangement and Distance of Liquid). Box \#3: Because the water molecules will combine the sugar molecules to produce solution (Alternative Movement of Aqeous)]. This is due to the fact that student often perceive particles of matter as static, particularly in the solid state, where on contrary the particles in all three states of matter are in continuous motion or vibration [25]. This finding is supported by Johnson [12] who claimed that students easily utilize the idea of the intrinsic motion of particles in the gas state, but when they were probed to explain why sugar dissolves when left in water without stirring, almost none of the students were able to relate this process to the ideas of intrinsic motion of the water particles. An interview excerpt from study adequately exemplifies the way in which students think about the motion of particles in three states of matter "the sugar particles would be staying still, the water particle moving around a bit and the gas particle flying off”.

The movement and uniform distribution of liquid molecules in another liquid

\section{TABLE X. PERCENTAGES OF STUDENTS’ DRAWING WITH ALTERNATIVE CONCEPTION ON THE MOVEMENT AND UNIFORM DISTRIBUTION OF LIQUID MOLECULES IN ANOTHER LIQUID}

\begin{tabular}{|c|c|c|}
\hline Concept & Frequency (N) & Percentage (\%) \\
\hline $\begin{array}{c}\text { Food coloring } \\
\text { just added }\end{array}$ & 29 & 91 \\
\hline $\begin{array}{c}\text { After a period of } \\
\text { time }\end{array}$ & 12 & 38 \\
\hline
\end{tabular}

The data analysis of this paper demonstrated that majority of the students (91 percent) did not understand the concept of the movement and uniform distribution of liquid molecules in another liquid. This showed that the students did not understand that the molecules of food coloring diffuse through water from an area of high concentration to an area of low concentration due to their ability to move. This is due to the fact that food coloring molecules move and slowly diffuse from the top of the box before completely occupied the box. This food coloring encompasses discrete molecules which move randomly and diffuse to all directions in the liquid from high concentrated to low concentrated area. However, majority of the students failed to draw the condition of the particles when four food coloring molecules added to twelve water molecules. The students' drawing showed that alternative conception emerged against the arrangement and 
relative spacing between particles on submicroscopic level as shown in Figure 10.

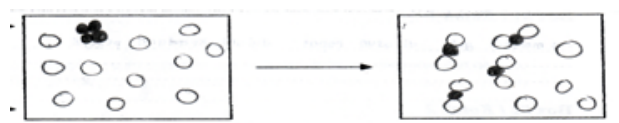

Fig. 13. Drawings that represent student 7's alternative conceptions of the mixture of food coloring and water molecules at the submicroscopic level

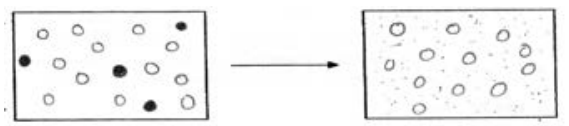

Fig. 14. Drawings that represent student 5's alternative conceptions of the mixture of food coloring and water molecules at the submicroscopic level

TABLE XIII. PERCENTAGES OF STUDENTS' EXPLANATION WITH ALTERNATIVE CONCEPTION ON THE MOVEMENT AND UNIFORM DISTRIBUTION OF LIQUID MOLECULES IN ANOTHER LIQUID

\begin{tabular}{|c|c|c|}
\hline Concept & Frequency (N) & Percentage (\%) \\
\hline $\begin{array}{c}\text { Movement and } \\
\text { distribution }\end{array}$ & 29 & 91 \\
\hline
\end{tabular}

The students' explanation also showed the disability of the student to grasp the concept efficiently based on their statement such as [Food colouring and water are liquid so arrangement are freely but fixed (Alternative Arrangement and Distance of Liquid). After a period of time, the food colouring is mixed with water molecules (Alternative Movement of Liquid)]. Only three students were able to accurately explain the movement and uniform distribution of liquid molecules in another liquid. This is due to the fact that the students were not able to understand the concept that particles of liquid move randomly and collide against each other. This finding is parallel with Lee [14] who find that students had no concept of empty space between molecules, molecules being the same size as tiny objects and that molecules are not constantly moving. C. Is there a significant difference between male and female
students on achievement in PNM concept?

TABLE XV. ANALYSIS OF T-TEST IN COMPARING THE ACHIEVEMENT LEVEL OF PNM CONCEPT ACROSS GENDER

\begin{tabular}{|c|c|c|c|c|c|}
\hline Gender & n & Mean & SD & t & p \\
\hline Male & 14 & 45.71 & 12.688 & -1.058 & 0.076 \\
\cline { 1 - 3 } Female & 18 & 49.44 & 7.048 & & \\
\hline
\end{tabular}

significant of confidence level of $0.05(p \leq 0.05)$

Table XV show the results of comparative studies of achievement level of PNM concept across gender. T-test

Identify applicable sponsor/s here. If no sponsors, delete this text box (sponsors). analysis showed that there was no significant difference between the achievement level of the concept of male and students to female students, The value of 'p' obtained was 0.076 and set significance level is 0.05 (5\%). The value of ' $p$ ' is high to show any tendency towards the significance. Other research also showed no gender differences in various topics in chemistry such as the mole [40] and volume [41]. This shows that there is no difference between male and female students on the achievement due to the teaching practice gender fairness during teaching and learning process. All students, regardless of gender can do all teaching and learning activities without and gender aggregation.

\section{CONCLUSION}

In summary, the results indicated that student responses were categorized in the alternative understanding with scientific fragments categories. Similar alternative views are also reported in literature [37-38]. Many students could not learn the concepts related to submicroscopic level of particles such as the arrangement and relative spacing between the particles in three states of matter, the movement of water particles and solid particles in a liquid and the movement and uniform distribution of liquid molecules in another liquid well enough. This is because many students do not have a concrete idea of what the particulate nature of matter means, so they cannot manipulate this theory and therefore do not understand its implications for ideas such as gases. Although students are generally familiar with atoms, molecules and generally particles concepts from school and they know that matter is made up from discrete particles, they are reluctant to use the particulate nature of matter to explain observable phenomena and attribute the macroscopic properties of matter to the submicroscopic level [39]. Teaching methods, memorization of the concepts, making science lesson without laboratory, insufficient curriculum and tradisional learning activities may be the reasons.

Although this paper was small in scope and needs to be replicated on a much larger scale, it seems to indicate that instruction on the particulate nature of matter is effective in helping students make connections between the three levels on which chemistry can both taught and understood. It is recommended by this paper that by emphasizing the three levels of chemistry to describe common, everyday phenomena to which students could relate would make the instruction more effective. Boz [37] suggest that teachers in science classroom should encourage the students to use the particulate nature of matter in explaining daily-life related events to prevent rote learning and to facilitate conceptual understanding of the particle theory. For this suggestion, teacher should also be equipped with the necessary capabilities of continuously identifying their own students' conceptions and implementing teaching approaches that promote conceptual understanding.

\section{ACKNOWLEDGMENT}


The preferred spelling of the word "acknowledgment" in America is without an "e" after the "g." Avoid the stilted expression "one of us (R. B. G.) thanks ...”. Instead, try "R. B. G. thanks...”. Put sponsor acknowledgments in the unnumbered footnote on the first page.

\section{REFERENCES}

[1] A. H. Johnstone, Why is science difficult to learn? things are seldom what they seem, Journal of Computer Assisted Learning, vol.7, pp. 75-83, 1991.

[2] E. J. Yezierski and J. P. Birk, Misconceptions about the particulate nature of matter. Using animations to close the gender gap, Journal of Chemical Education, vol.83, pp. 954-960, 2006.

[3] P. W. Hewson and M. G. A. B. Hewson, "The status of students' conceptions," in Research in Physics Learning: Theoretical Issues and Empirical Studies, R. Duit, F. Goldberg, and H. Niedderer, Eds. Kiel, Germany: Institute for Science Education at the University of Kiel, 1992, pp.59-73.

[4] G. Nicoll, A qualitative investigation of undergraduate chemistry students' macroscopic interpretations of the submicroscopic structure of molecules, Journal of Chemical Education, vol. 80, pp. 205-213, 2003.

[5] R. Kozma and J. Russell, Multimedia and understanding: expert and novice responses to different representations of chemical phenomena, Journal of Research in Science Teaching, vol.34, pp. 949-968, 1997.

[6] D. L. Gabel, "The complexity of chemistry and implications for teaching," in International Handbook of Science Education, B. J. Fraser and K. G. Tobin, Eds. Great Britain: Kluwer Academic Publishers, 1998, pp. 233-248.

[7] R. Ben-Zvi, B. Eylon, and J. Silberstein, Is an atom of copper malleable?, Journal of Chemical Education, vol.63, pp. 64-66, 1986.

[8] G. D. Chittleborough, The role of teaching models and chemical representations in developing students' mental models of chemical phenomena, Ph.D. Thesis, 2004

[9] J. Snir, G, Raz, and C. L. Smith, Linking phenomena with competing underlying models: a software tool for introducing students to the particulate model of matter, Science Education, vol.87, pp. 794-830, 2003.

[10] D. F. Treagust, A. L. Chandrasegaran, J. Crowley, B. H. W. Yung, I. P.A. Cheong, and J. Othman, Evaluating students' understanding of kinetic particle theory concepts relating to the states of matter, changes of state and diffusion: a cross-national study, International Journal of Science and Mathematics Education, vol.8, pp. 141-164, 2010.

[11] A. K. Griffiths and K. R. Preston, Students' misconceptions relating to fundamental characteristics of atoms and molecules, Journal of
Research in Science Teaching, vol.29, pp. 611-628, 1992.

[12] P. Johnson, Progression in children's understanding of a 'basic' particle theory: a longitudinal study, International Journal of Science Education, vol.20, pp. 393-412, 1998.

[13] K. Johnston, "Students' responses to the active learning approach to teaching the particulate theory of matter, " in Relating Macroscopic Phenomena to Microscopic Particles, P. L. Lijnse, P. Licht, W. de Vos and A. J. Waarlo, Eds. Utrecht, The Netherlands: Centre for Science and Mathematics Education, 1990, pp. 247-265.

[14] O. Lee, D. C. Eichinger, C. W. Anderson, G. D. Berkheimer, and T. D. Blakeslee, Changing middle school students' conceptions of matter and molecules, Journal of Research in Science Teaching, vol.30, pp. 249-270, 1993.

[15] M. B. Nakhleh and A. Samarapungavan, Elementary school children's beliefs about matter, Journal of Research in Science Teaching, vol.36, pp. 777-805, 1999.

[16] M. B. Nakhleh, A. Samarapungavan, and Y. Saglam, Middle school students' beliefs about matter, Journal of Research in Science Teaching, vol.42, pp. 581612, 2005.

[17] S. Novick and J. Nussbaum, Pupil's understanding of the particulate nature of matter: a cross-age study, Science Education, vol.65, pp. 187-196, 1981.

[18] M. P. Pereira and M. E. M. Pestana, Pupils' representations of models of water, International Journal of Science Education, vol.13, pp. 313-319, 1991.

[19] J. I. Pozo and M. Á. Gómez-Crespo, The embodied nature of implicit theories: the consistency of ideas about the nature of matter, Cognition and Instruction, vol. 23, pp. 351-387, 2005.

[20] P. H. Scott, "Pathways in learning science: a case study of the development of one student's ideas relating to the structure of matter," in Research in Physics Learning: Theoretical Issues and Empirical Studies, R. Duit, F. Goldberg and H. Niedderer, Eds. Kiel, Germany: Institute for Science Education at the University of Kiel, 1992, pp. 203-224.

[21] M. Sequeira and L. Leite, “On relating macroscopic phenomena to microscopic particles at the junior high school level," in Relating Macroscopic Phenomena to Microscopic Particles, P. L. Lijnse, P. Licht and W. de Vos, Eds. Utrecht, The Netherlands: Centre for Science and Mathematics Education, 1990, pp. 220231.

[22] C. C. Tsai, Overcoming junior high school students' misconceptions about microscopic views of phase change: a study of an analogy activity, Journal of Science Education and Technology, vol.8, pp. 83-91, 1999. 
[23] G. V. Thomas and A. M. J. Silk, An introduction to the psychology of children's drawings, Hemel Hempstead: Harvester Wheat Sheaf, 1990.

[24] L. J. Rennie and T. Jarvis, Children's choice of drawings to communicate their ideas about technology, Research in Science Education, vol.25, pp. 239-252, 1995.

[25] E. Adadan, Promoting high school student's conceptual understandings of the particulate nature of matter through multiple representations, Ph.D. Thesis, 2006.

[26] M. R. Abraham, M. R. Williamson, V. M. Williamson and S. L. Westbrook, A cross-age study of the understanding of five chemistry concepts, Journal of Research in Science Teaching, vol.31, pp. 147-165, 1994.

[27] A. Ayas and H. Özmen, A study of students’ level of understanding of the particulate nature of matter at secondary school level, Bogazici University Journal of Education, vol.19, pp. 45-60, 2002.

[28] A. Ayas., H. Özmen, and M. Çalık, Students' conceptions of the particulate nature of matter at secondary and tertiary level, International Journal of Science and Mathematics Education, vol.8, pp. 165184, 2010.

[29] B. Coştu, Learning science through the PDEODE teaching strategy: helping students make sense of everyday situations, Eurasia Journal of Mathematics, Science \& Technology Education, vol.4, pp. 3-9, 2008.

[30] M. B. Nakhleh, Why some students don't learn chemistry: chemical misconceptions, Journal of Chemical Education, vol.69, pp. 191, 1992.

[31] A. G. Harrison and D. F. Treagust, "The particulate nature of matter: challenges in understanding the submicroscopic world," in Chemical Education: Towards Research-Based Practice, J. K. Gilbert, O. D. Jong, R. Justi, D. F. Treagust, and J. H. Van Driel. Dordrect, Kluwer Academic, 2002, pp.189-212.

[32] R. Ben-Zvi, J. Silberstein, and R. Mamlok, "Macromicro relationships: a key to the world of chemistry," in Relating macroscopic phenomena to microscopic particles. A central problem in secondary science education, P. L. Lijnse, H. M. C. Eijkelhof, P. Licht, W. De Vos, and and A. J. Waarlo, Eds. University of Utrecht, 1990, pp. 184-197.

[33] M. Allen, Misconceptions in primary science, England: Open University Press, 2010.

[34] J. Nussbaum, "the particulate nature of matter in the gaseous phase," in Children's Ideas in Science, R. Driver, E. Guesne, and A. Tiberghien, Eds. USA: Open University Press, 1985.

[35] R. Stavy, Children's conception of changes in the state of matter; from liquid (or solid) to gas, Journal of Research in Science Teaching, vol.27, pp.247-266, 1990.

[36] R. Stavy, Children's conception of gas, International Journal of Science Education, vol.10, pp. 553-560, 1988)

[37] Y. Boz, Turkish pupils' conceptions of the particulate nature of matter, Journal of Science Education and Technology, vol.15, pp.203-213, 2006.

[38] A. Ayas, H. Ozmen, B. Costu, Establishment for high school students understanding levels on evaporation, Dokuz Eylul University, Buca Education Faculty Magazine, vol.14, pp. 74-84, 2002.

[39] H. Özmen, Effect of animation enhanced conceptual change texts on $6^{\text {th }}$ grade students' understanding of the particulate nature of matter and transformation during phase changes, Computers \& Education, vol.57, pp. 1114-1126, 2011.

[40] S.Yalcinalp, O. Geban, and I. Ozkam, Effectiveness of using computer-assisted supplementary instruction for teaching the mole concept, Journal of Research in Science Teaching, vol.32, pp. 1083-1095, 1995.

[41] B. Choi and E. Genaro, The effectiveness of using computer simulated experiments on junior high students' understanding of the volume displacement concept, Journal of Research on Computing in Education, vol.24, pp. 539-552, 1987.

\section{Creative Commons Attribution License 4.0 (Attribution 4.0 International, CC BY 4.0)}

This article is published under the terms of the Creative Commons Attribution License 4.0

https://creativecommons.org/licenses/by/4.0/deed.en_US 